\title{
Evaluation of Bone Regeneration of Simvastatin Loaded Chitosan Nanofiber Membranes in Rodent Calvarial Defects
}

\author{
Najib Ghadri'1, K. Mark Anderson ${ }^{2}$, Pradeep Adatrow ${ }^{1}$, Sidney H. Stein ${ }^{1}$, Hengjie Su${ }^{3}$, \\ Franklin Garcia-Godoy ${ }^{4}$, Anastasios Karydis ${ }^{1}$, Joel D. Bumgardner ${ }^{3}$ \\ ${ }^{1}$ Department of Periodontology, University of Tennessee Health Science Center, College of Dentistry, Memphis, USA \\ ${ }^{2}$ Department of Diagnostic Sciences and Oral Medicine, University of Tennessee Health Science Center, College of Dentistry, \\ Memphis, USA \\ ${ }^{3}$ Department of Biomedical Engineering, University of Memphis, Herff College of Engineering, Memphis, USA \\ ${ }^{4}$ Department of Bioscience Research, University of Tennessee Health Science Center, College of Dentistry, Memphis, USA \\ Email: mghadri1@uthsc.edu
}

How to cite this paper: Ghadri, N., Anderson, K.M., Adatrow, P., Stein, S.H., Su, H.J., Garcia-Godoy, F., Karydis, A. and Bumgardner, J.D. (2018) Evaluation of Bone Regeneration of Simvastatin Loaded Chitosan Nanofiber Membranes in Rodent Calvarial Defects. Journal of Biomaterials and Nanobiotechnology, 9, 210-231.

https://doi.org/10.4236/jbnb.2018.92012

Received: March 16, 2018

Accepted: April 24, 2018

Published: April 27, 2018

Copyright $\odot 2018$ by authors and Scientific Research Publishing Inc. This work is licensed under the Creative Commons Attribution International License (CC BY 4.0).

http://creativecommons.org/licenses/by/4.0/

\begin{abstract}
Chitosan nanofiber membranes have been known to have a high degree of biocompatibility and support new bone formation with controllable biodegradation. The surface area of these membranes may allow them to serve as local delivery carriers for different biologic mediators. Simvastatin, a drug commonly used for lowering cholesterol, has demonstrated promising bone regenerative capability. The aim of this study was to evaluate simvastatin loaded chitosan nanofiber membranes for guided bone regeneration (GBR) applications and their ability to enhance bone formation in rat calvarial defects. Nanofibrous chitosan membranes with random fiber orientation were fabricated by electrospinning technique and loaded with $0.25 \mathrm{mg}$ of simvastatin under sterile conditions. One membrane was implanted subperiosteally to cover an $8 \mathrm{~mm}$ diameter critical size calvarial defect. Two groups: 1) Control: non-loaded chitosan membranes; 2) Experimental: chitosan membranes loaded with $0.25 \mathrm{mg}$ of simvastatin were evaluated histologically and via micro-computed tomography (micro-CT) for bone formation at 4 and 8 weeks time points ( $\mathrm{n}=5$ /group per time point). Both groups exhibited good biocompatibility with only mild or moderate inflammatory response during the healing process. Histologic and micro-CT evaluations confirmed bone formation in calvarial defects as early as 4 weeks using control and experimental membranes. In addition, newly-formed bony bridges consolidating calvarial defects histologically along with partial radiographic defect coverage were observed at 8 weeks in both groups. Although control and experimental groups
\end{abstract}


demonstrated no significant statistical differences in results of bone formation, biodegradable chitosan nanofiber membranes loaded with simvastatin showed a promising regenerative potential as a barrier material for guided bone regeneration applications.

\section{Keywords}

Guided Bone Regeneration (GBR), Chitosan, Simvastatin, Calvarial Defect, Membrane, Nanofiber

\section{Introduction}

Guided bone regeneration (GBR) technique is a widely utilized surgical approach in the augmentation of alveolar bone deformities that are frequently observed in edentulous patients. A wide range of nonresorbable and resorbable barrier membranes are currently used in GBR procedures to prevent soft tissue infiltration and achieve osseous tissue formation [1]. Among these, nonresorbable membranes such as polytetrafluoroethylene are susceptible to contamination during exposure and require a second surgery for membrane removal [2]. On the other hand, resorbable membranes, like collagen, often exhibit premature degradation, which limits volume of bone formation [3].

Chitosan is a natural co-polymer composed of $\mathrm{N}$-acetyl-glucosamine and glucosamine units, and has been investigated as an alternative material in bone tissue regeneration due to its well described biocompatible and biodegradable properties [4]. In addition, several studies have reported chitosan to have antibacterial and hemostatic activities as well as to promote osteoprogenitor cell differentiation and mineralization [5] [6] [7] [8] [9]. Because of these properties, chitosan has been investigated in both GBR and guided tissue regeneration (GTR) and these studies have generally reported the ability of chitosan to support new cementum and bone formation [10]-[16]. The potential of chitosan as a GBR material may be enhanced using the electrospinning process to form nanofibrous barrier membranes [12] [13] [14] [15] [16]. Use of nanofibrous membranes offers many advantages, including small pore sizes of $100-200 \mathrm{~nm}$, which prevents soft tissue infiltration and maintains effective barrier function, while mimicking native extracellular fibrous structure favorable to cell growth and tissue healing [12]-[21]. Moreover, the nanofiber structure increases the membrane's surface area which has advantages for incorporation and local delivery of molecules to enhance membrane regenerative properties [22].

Many studies examining chitosan membranes have focused on the incorporation of growth factors such as bone morphogenetic proteins (BMPs) and platelet derived growth factor (PDGF) to enhance bone regeneration in GBR applications [23] [24] [25] [26]. These studies report that incorporation of these growth factors into the chitosan materials resulted in marked increase in new bone formation with rapid calcification [23] [24] [25] [26]. While these growth factors 
may improve the bone regenerative capability of the chitosan membranes, they are associated with high costs due to the supra-physiological doses needed, which can result in adverse effects including root resorption and ankyloses, thus limiting their clinical benefits [27]-[32].

Simvastatin, an affordable and widely used hypolipidemic agent in the management of cardiovascular diseases, may be a promising alternative to these growth factors for bone healing stimulation. Early human studies reported an association between systemic statin use and reduced risk of hip fracture as well as increased bone density [33] [34] [35]. This effect of simvastatin on bone formation is explained through a variety of in vitro observations. Simvastatin has the ability to upregulate BMP- 2 mRNA expression in human mesenchymal stem cells [36]. In addition, osteogenic differentiation of human periodontal ligament stem cells cultured with simvastatin was enhanced and characterized by elevated expression levels of osteogenic markers such as alkaline phosphatase, bone sialoprotein, and BMP-2 [37]. In fact, simvastatin has the ability to antagonize tumor necrosis factor-alpha (TNF- $\alpha$ ), an inflammatory cytokine that inhibits osteogenesis, and subsequently upregulate the expression of BMP-2 in osteoblasts [38]. Furthermore, simvastatin can promote osteoblastic differentiation by stimulating vascular endothelial growth factor (VEGF) expression in osteoblasts and reduce osteoclastic activity, both of which lead to improved osteogenesis [39] [40]. The literature also reports that simvastatin possesses anti-inflammatory and antimicrobial properties that may play an important role in situations where infection may interfere with bone regeneration [41] [42].

In recent years much attention has been focused on local delivery strategies of simvastatin to allow adequate dosage at the desired site and avoid systemic side effects such as liver toxicity and myositis. Locally delivered simvastatin is reported to positively influence bone regeneration in the treatment of periodontal disease, maxillary sinus augmentation and enhance osseointegration around dental implants [43] [44] [45] [46] [47]. Bone re-generation was also higher when simvastatin was utilized locally in defects of calvaria, mandible and tibia osteotomy animal models [48]-[53].

By taking advantage of drug loading and local delivery potential of nanofiber chitosan membranes with the potential of simvastatin as an alternative to expensive growth factors, the ability of chitosan nanofiber GBR membranes to support bone regeneration in alveolar bone deformities may be enhanced. Therefore, the aim of this study was to evaluate simvastatin loaded chitosan nanofiber membranes ability to enhance bone formation in a critical sized rat calvarial defect model.

\section{Materials and Methods}

\subsection{Preparation of Chitosan Membranes}

Nanofibrous chitosan membranes with random fiber orientation were fabricated by electrospinning a $5.50 \mathrm{wt} \%$ chitosan (degree of deacetylation $(\mathrm{DDA})=70 \%$ 
deacetylated, molecular weight $(\mathrm{MW})=311.5 \mathrm{KDa}$, Primex) in $70 \%$ trifluoroacetic acid and $30 \%$ methylene chloride solution in a syringe with a blunt 20 gauge needle, at $25 \mathrm{kV}$ voltage as previously described [13]. Briefly, the nanofibers were collected on a $38.1 \mathrm{~cm}$ non-stick aluminum foil target positioned 15 $\mathrm{cm}$ from needle tip and rotated at $8.4 \mathrm{rpm}$ by an AC motor [13]. Membranes were cut into $14 \mathrm{~mm}$ diameter disks. Ten $\mathrm{mg}$ of electrospun nanofiber membrane disks were treated in a 50\% butyric anhydride in pyridine solution for $1 \mathrm{hr}$ with stirring at room temperature to create a butyryl-modified membrane (Figure 1(A)).

The addition of the butyric fatty acid molecule to the outside of the chitosan nanofibers increases the hydrophobic characteristics of the membrane and retains the nanofiber morphology when immersed in aqueous solutions [54]. Following treatment, membranes were rinsed in 3 changes of $1 \mathrm{~L}$ volumes of distilled water at $8 \mathrm{hr}$ intervals to remove residual salts from electrospinning solvent [54]. The membranes were then dried by lyophilization and sterilized by ethylene oxide gas ( $24 \mathrm{~h}$ exposure, $2 \mathrm{~h}$ ventilation, $20^{\circ} \mathrm{C}$ and $>35 \%$ relative humidity) before implantation. Under sterile conditions, membranes were loaded with 0.25 $\mathrm{mg}$ simvastatin/membrane by allowing membranes to completely absorb $37 \mu \mathrm{l}$ of $6.8 \mu \mathrm{g} / \mathrm{ml}$ simvastatin (Merck \& Co., Whitehouse Station, NJ) in 100\% ethanol solution (Figure 1(B)). The simvastatin dosage used in this study is based on the findings of previous studies reporting that local simvastatin doses ranging from 0.1 to $0.5 \mathrm{mg}$ enhanced bone formation in calvarial bone defects with minimal inflammatory response [49] [52].

\subsection{Experimental Design}

In this study, two nanofiber chitosan membranes were compared: 1) plain chitosan membranes as control; and, 2) chitosan membranes loaded with $0.25 \mathrm{mg}$ of simvastatin/implant as experimental group. All animal procedures were in compliance with the Guide for the Care and Use of Laboratory Animals and the
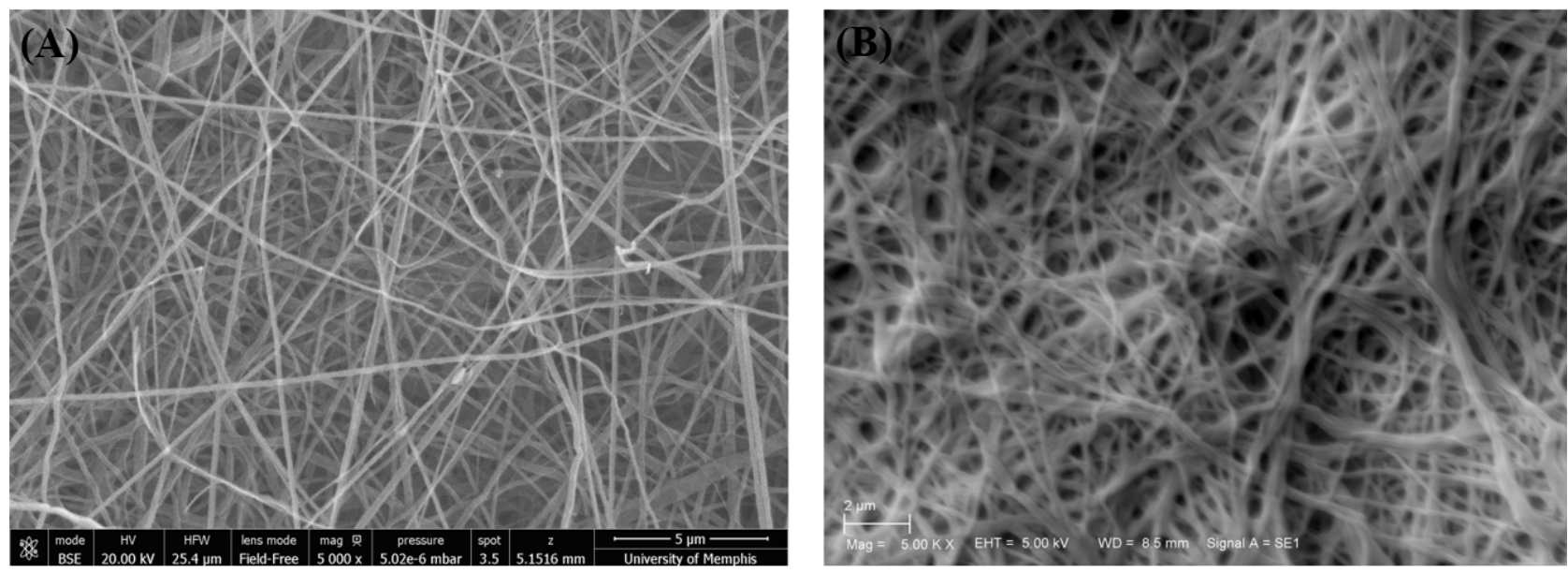

Figure 1. Scanning electron microscopy (SEM) graphs of (A) Butyryl-modified nanofibrous chitosan membranes, 5000×; (B) Simvastatin loaded butyryl-modified nanofibrous chitosan membranes, 5000x. 
University of Memphis Institutional Animal Care and Use Committee (Protocol No. 0747). A critical size calvarial defect of $8 \mathrm{~mm}$ in diameter was created in 25 Sprague-Dawley rats (approximately 2 months of age and $370 \mathrm{~g}$ ). Animals were randomized into 4 groups ( $\mathrm{n}=5$ /group per time point). 1 - 2 animals were added to each group to compensate for sample attrition due to death of animals. These animals were selected because they provide adequate size and tissue volume for testing the membranes, and are widely accepted for determining wound healing and tissue response to the implanted membranes. Briefly, rats were anesthetized with an inhalation of isoflurane (1\%) in an oxygen carrier. A midline incision in the skin over the cranium was made from the middle of the nasal bones to the posterior nuchal line $(\sim 20 \mathrm{~mm})$. The underlying soft tissue and periosteum were incised and reflected to expose the calvaria. An 8-mm diameter circular craniotomy was made in the center of the exposed calvaria using a custom trephine bur (Figure 2(A)). The drilling site was irrigated with sterile saline to limit heating during defect creation. The cranium disk was carefully dissected away while avoiding dural perforations and superior sagittal sinus intrusions. Rats were randomly assigned to either experimental or control groups. One membrane (14 $\mathrm{mm}$ in diameter) was implanted subperiosteally covering the critical defect by at least $3-4 \mathrm{~mm}$ (Figure 2(B)). Periosteum and skin were carefully repositioned and secured with polyglycolic acid (PGA) 3-0 after membrane implantation. Each rat received one membrane. Buprenorphine was administered for 2 days postoperatively as needed. At each time period, 4 and 8 weeks, five animals per group with the exception of 6 animals for experimental group at 8 weeks, were euthanized and calvaria, including implanted membranes, were retrieved for micro-Computed Tomography (micro-CT) and histological evaluations.

\subsection{Micro-Computed Tomography Analysis}

Retrieved calvarial samples were fixed in 10\% neutral buffered formalin for 72 hours and transferred to phosphate-buffered saline (PBS). High resolution micro-CT was utilized to scan and evaluate the healing and mineralization of the
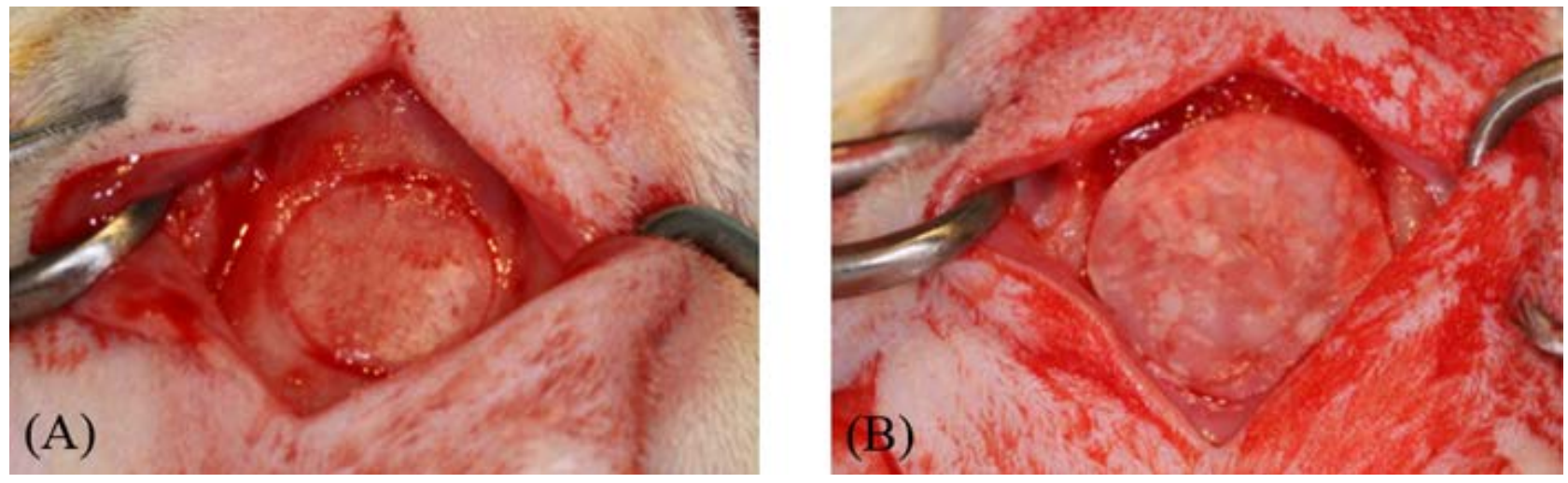

Figure 2. (A) Defect outline was demarcated using a trephine bur. Calvarial disk was carefully removed and bony defect ( $8 \mathrm{~mm}$ in diameter) was created; (B) Defect coverage with membrane. 
calvarial defects. The entire heads were scanned in a $12.3-\mathrm{mm}$ diameter sample holder at $8 \mu \mathrm{m}$ resolution, energy level of $55 \mathrm{kV}$, and intensity of $72 \mu \mathrm{A}$ on a CT440 scanner (Scanco Medical, Basserdorf, Switzerland). Data were reconstructed using the Scanco Imaging processing software for further morphometric and density analysis. Reorientation of the reconstructed micro-CT graphs was done using data viewer software (Bruker AXS Inc.) Volume of Interest was identified as a cylinder that corresponded and overlapped the original defect's shape, volume and location. Height of cylinder was extended $0.1-0.2 \mathrm{~mm}$ superior and inferior to defect to allow for accurate measurements [15]. The principal axes of the dataset were aligned with the principal axes of the calvarial defect along the centraxonial direction of the cylinder. Morphometric analysis for percent new bone volume to defect volume, bone mineral density and ratio of new bone surface area to bone volume were carried out with the Mimics Research Software 18.0.0.525 (Materialise NV, Leuven, Belgium).

\subsection{Histological Analysis}

Previously scanned samples were then decalcified and prepared for paraffin embedding and staining with hematoxylin and eosin (H\&E). Embedded samples were sectioned in the sagittal direction into $4 \mu \mathrm{m}$ serial slices through the middle of the calvarial defect. Hematoxylin and eosin staining provided a general histological overview of membrane shape and structure, new bone formation in defect and appearance of surrounding soft tissues. Sections were viewed and inflammatory reaction was graded by a blinded pathologist using a 4-point scoring system $(0=$ absent, $1=$ mild, $2=$ moderate, and $3=$ severe $)$ to determine the tissue reaction to the membranes and to observe membrane degradation [15]. A score of 0 was considered as a total absence of neutrophils, lymphocytes and macrophages. A score of 1 showed as primarily lymphocytes with very few neutrophils, as well as some minor macrophages and focal foreign body reaction. A score of 2 was characterized by greater presence of macrophages, lymphocytes and foreign body reaction, especially the foreign body response. A score 3 was typically determined by even greater numbers of lymphocytes, macrophages and significant foreign body reaction with heavy abscess formation. Using the BioquantOsteo II v.8.10.20 imaging system (BIOQUANT Image Analysis Corporation, Nashville, TN) the following measurements were calculated: percentage of new bone/total defect area and percentage of chitosan membrane/total defect area.

\subsection{Statistical Analysis}

Ninety-five percent confidence intervals were calculated and used to compare the ordinal inflammatory response scores. Two-way ANOVA at the 0.05 level of significance was used to compare the mean values of the histologic and micro CT measurements in the control and experimental groups at 4 and 8 week time points. 


\section{Results}

\subsection{Clinical Observations}

Surgical procedures were performed without complications on 21 rats and animals recovered well after surgery. Four rats were lost following surgery due to post-operative bleeding and intra-operative brain tissue trauma. For surviving animals, calvarial wounds healed predominantly uneventfully without showing clinical signs of inflammation. Primary closure of wound area was maintained throughout the experiment. Following retrieval, visual examination of the specimens revealed membranes that were still present covering the defect in the rat calvaria (Figure 3(A) and Figure 4(A)). Overall, control membranes were more easily visualized than the experimental membranes at 4- and 8-week time points (Figure 3(A) and Figure 4(A)). Numerous specimens showed folding of the membrane towards the center of the defect.

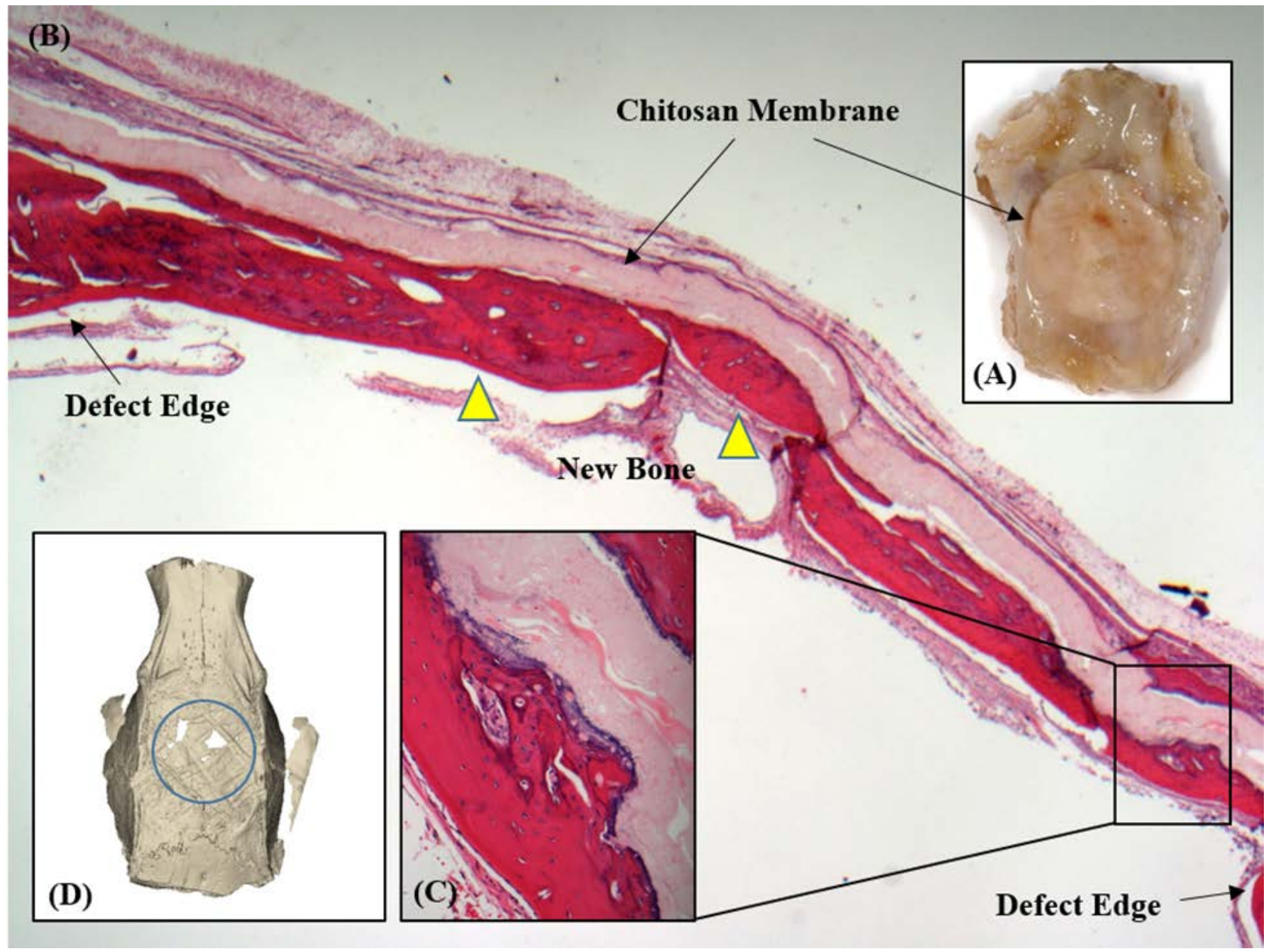

Figure 3. Representative H\&E stain histologic, clinical, and micro-CT model views of a calvarial defect in control group at 8 weeks. (A) Photograph of the retrieved sample showing membrane and surrounding soft and calvarial bone tissues; (B) Histologic view of the sample. Yellow triangles point out to the new bony bridge in the middle portion of the defect (original magnification $\times 2$ ); (C) Higher magnification histologic view of newly-formed bone in the defect (original magnification $\times 20$ ); (D) $3 \mathrm{D}$ view of the $\mu \mathrm{CT}$ model of the retrieved sample. Blue circle represents the calvarial defect. 


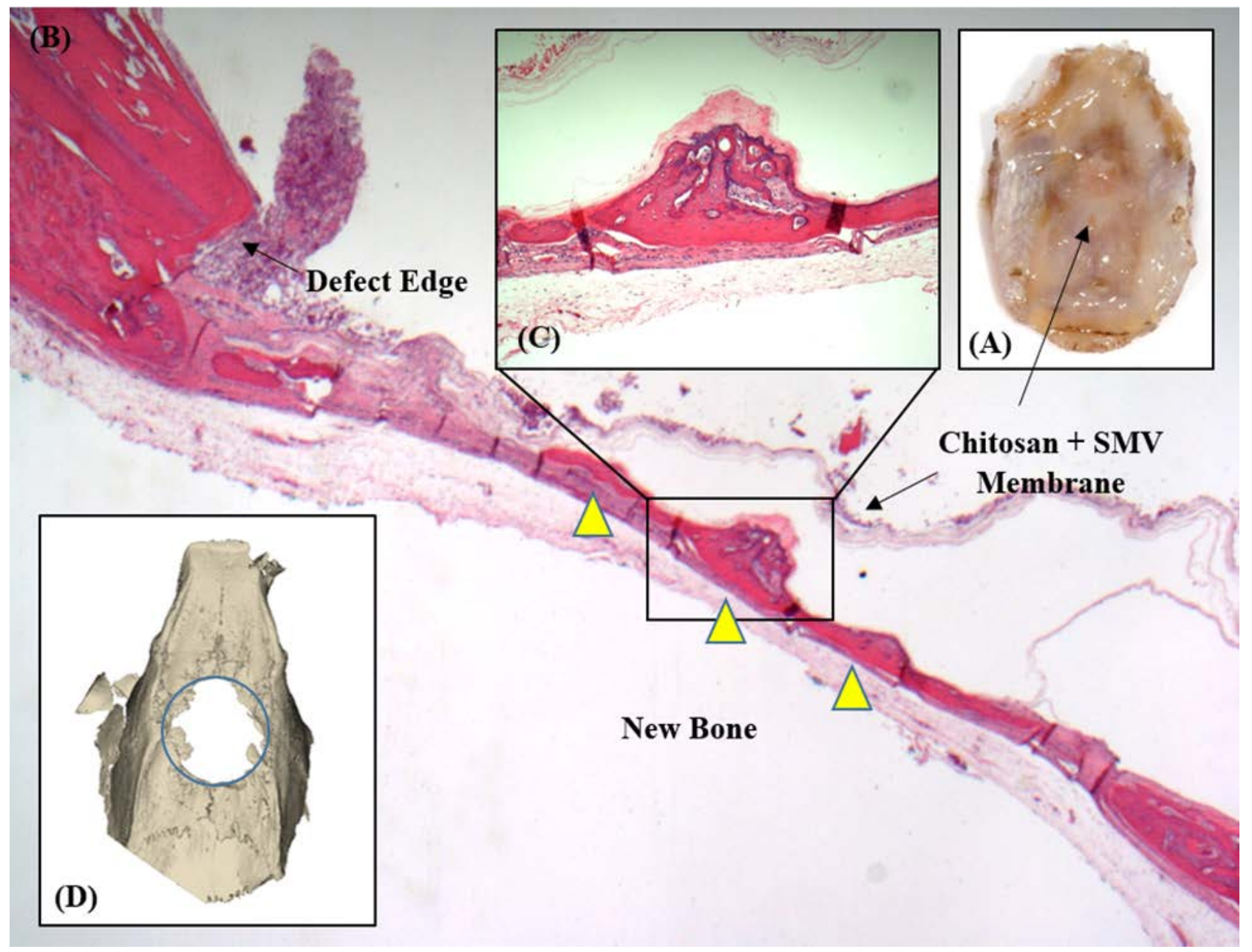

Figure 4. Representative H\&E stain histologic, clinical, and micro-CT model views of calvarial defect in experimental simvastatin (SMV) group at 8 weeks. (A) Photograph of the retrieved sample showing membrane and surrounding soft and calvarial bone tissues; (B) Histologic view of the sample. Yellow triangles point out to the new bony bridge in the middle portion of the defect (original magnification $\times 2$ ); (C) Higher magnification histologic view of newly-formed bone in the defect (original magnification $\times 10)$; (D) $3 \mathrm{D}$ view of the $\mu \mathrm{CT}$ model of the retrieved sample. Blue circle represents the calvarial defect.

\subsection{Histologic Evaluation of Biocompatibility and Degradation}

In general, no adverse histological reaction was observed in the tissues surrounding the implanted membranes. At 4 weeks most specimens in both groups showed mild granulation tissue response with mainly neutrophilic migration towards the membrane surface along with few foreign-body giant cells (Figure 5). Angiogenic activity represented by capillary formation associated with the membrane surface was observed in both groups (Figure 5). Resolution of inflammation was seen histologically in specimens collected at 8 weeks. Inflammatory cells were rarely evident and fibroblasts were seen at the periphery of control and experimental membranes (Figure 3(B) and Figure 4(B)).

The inflammatory response against these materials was assessed using the 4-point scoring system. As shown in Table 1, inflammation scores for both groups did not change significantly at 4 - and 8 -week time points $(p>0.05)$. 

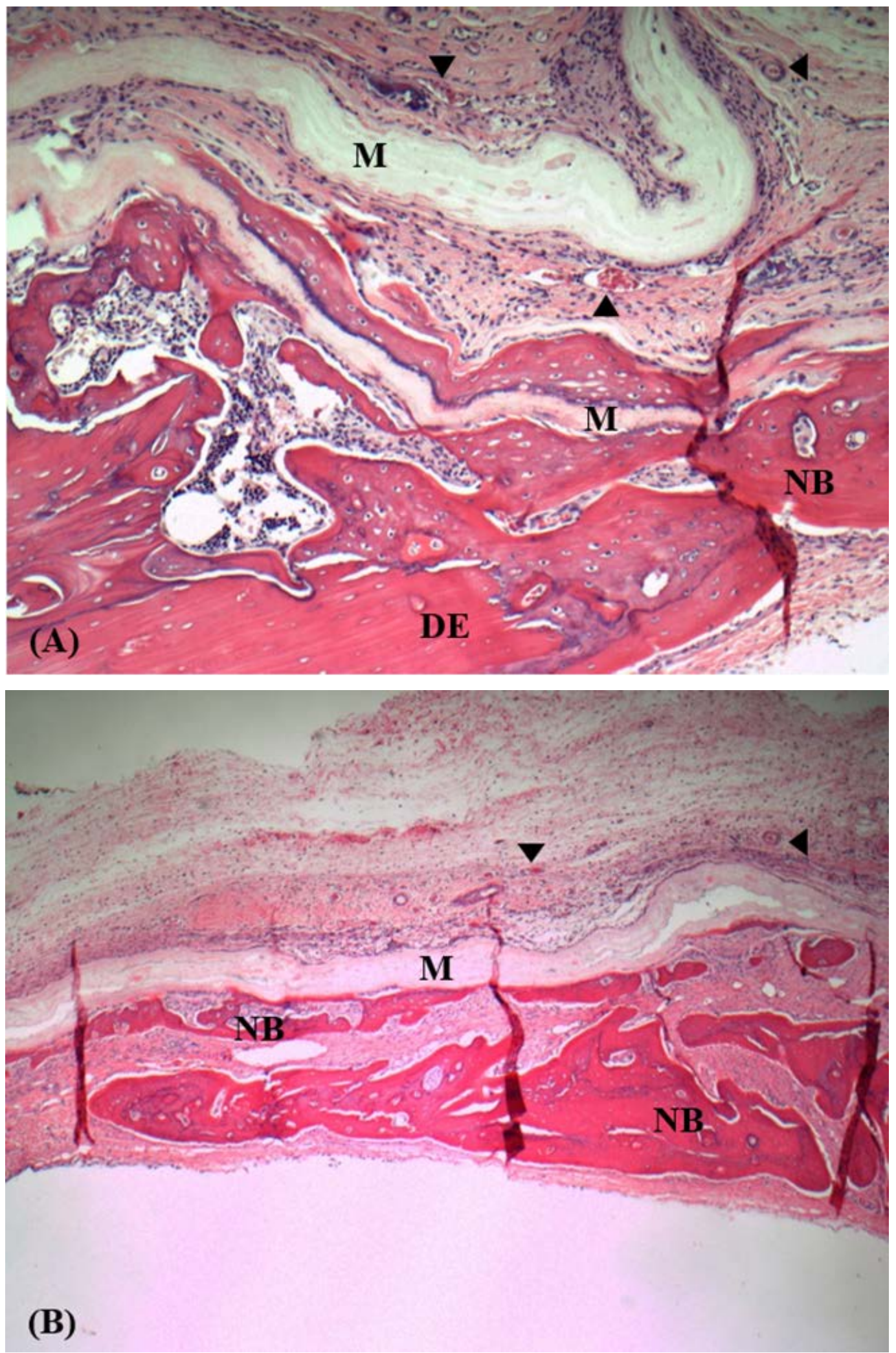

Figure 5. Histologic views of calvarial defects at 4 weeks: (A) Control group (original magnification $\times 10$ ). M: Chitosan membrane; NB: New bone; DE: Defect edge; Black arrows indicate blood vessels; (B) Experimental group (original magnification $\times 4$ ). M: Chitosan + Simvastatin membrane; NB: New bone; Black arrows indicate blood vessels. 
Table 1. The 95\% confidence intervals for scores of inflammation response ${ }^{a}$ to control and experimental chitosan membranes covering $8 \mathrm{~mm}$ rat calvarial defects.

\begin{tabular}{ccc}
\hline \multirow{2}{*}{ Membrane Type } & \multicolumn{2}{c}{ Confidence Interval $^{\mathrm{b}}$} \\
\cline { 2 - 3 } & 4 weeks & 8 weeks \\
\hline Chitosan & 0.64 to 1.75 & 0.91 to 2.28 \\
& $($ mean $=1.2)$ & $($ mean $=1.6)$ \\
Chitosan + Simvastatin & 0.98 to 2.28 & 1.12 to 2.20 \\
& $($ mean $=1.6)$ & $($ mean $=1.6)$ \\
\hline
\end{tabular}

Regarding degradation, membranes in the control and experimental groups presented with minimal to no change of shape and structure at 4 weeks (Figure 5). The membrane outline was clearly demarcated from surrounding connective tissue with few histological sections showing membrane fiber delamination. At 8 weeks, the membrane structure of control group presented to not be permeated with minimal signs of degradation (Figure 3(B) and Figure 3(C)). As bone continued to form in the defects, the membrane outline of experimental group was recognized and slightly showed more delamination of membrane material compared to control group (Figure 3(B) and Figure 4(B)).

Histomorphometric measurements of percent of membrane in defect area are shown in Table 2. The percentage of remaining membrane in defects at 4 weeks was $(24.79 \pm 10.72)$ vs $(25.07 \pm 22.86)$ for the control and experimental groups, respectively, with no statistically significant difference $(P>0.05)$. Membrane presence in defects decreased throughout the study period for both groups and was less in the experimental group $(14.90 \pm 17.07)$ vs $(18.69 \pm 13.37)$ in the control at 8 weeks. However, the differences were not statistically significant $(\mathrm{P}>$ $0.05)$.

\subsection{Histologic and Micro-CT Evaluation of Bone Formation}

As shown in Figure 5(A), newly-formed bone in the control group was detected at the edges of the defect at 4 weeks. In some specimens, bony islands were found in the central portion of the defect as well. Similar histological findings of bone formation were seen in the experimental group (Figure 5(B)). At 8 weeks, newly-formed bone islands were connected to each other at the center of the defect and partial to complete reunion of defect margins were evident histologically in both groups (Figure 3(B) and Figure 4(B)). Prominent bony bridges consolidating the calvarial defects were observed in some specimens as shown in Figure 3(B) for the control group. Bone formation adjacent to membranes exhibited a distinct woven immature pattern in close proximity to membrane surface and lamellar mature bone towards the periphery in both groups (Figures 3(C) and Figure $4(\mathrm{C})$ ). Formation of new bone was also observed within the folds and on both internal and external surfaces of the membrane (Figure 6).

Table 2 shows the histomorphometric measurements of bone formation for both groups at different time points. At 4 weeks, the percentage of new bone in 
Table 2. The histomorphometric and micro-CT results for bone healing with membranes in $8 \mathrm{~mm}$ rat calvarial defects at 4 weeks and 8 weeks. Values shown are mean $| \pm|(S D)$.

\begin{tabular}{|c|c|c|c|c|c|}
\hline & & \multicolumn{2}{|c|}{ Chitosan } & \multicolumn{2}{|c|}{ Chitosan + Simvastatin } \\
\hline & & 4 weeks & 8 weeks & 4 weeks & 8 weeks \\
\hline \multirow{2}{*}{$\begin{array}{l}\text { Histomorphometric } \\
\text { measurements } \\
\mathrm{M} \pm \mathrm{SD}\end{array}$} & $\begin{array}{c}\% \text { new bone/total } \\
\text { defect area }\end{array}$ & $20.87 \pm 13.86$ & $32.96 \pm 31.61$ & $10.08 \pm 9.87$ & $33.02 \pm 33.56$ \\
\hline & $\begin{array}{c}\% \text { membrane } / \text { defect } \\
\text { area }\end{array}$ & $24.79 \pm 10.72$ & $18.69 \pm 13.37$ & $25.07 \pm 22.86$ & $14.90 \pm 17.07$ \\
\hline \multirow{3}{*}{$\begin{array}{l}\text { Micro-CT analysis } \\
\qquad \mathrm{M} \pm \mathrm{SD}\end{array}$} & $\begin{array}{c}\% \text { new bone } \\
\text { volume/defect volume }\end{array}$ & 9. $40 \pm 6.21$ & $28.89 \pm 26.90$ & $10.63 \pm 9.98$ & $12.83 \pm 4.80$ \\
\hline & density $(\mathrm{g} / \mathrm{ml})$ & $1.61 \pm 0.05$ & $1.69 \pm 0.14$ & $1.62 \pm 0.04$ & $1.66 \pm 0.02$ \\
\hline & $\begin{array}{c}\text { new bone surface } \\
\text { area/new bone volume } \\
\left(\mathrm{mm}^{-1}\right)\end{array}$ & $23.19 \pm 5.40$ & $20.58 \pm 15.65$ & $26.88 \pm 9.21$ & $19.37 \pm 3.60$ \\
\hline
\end{tabular}

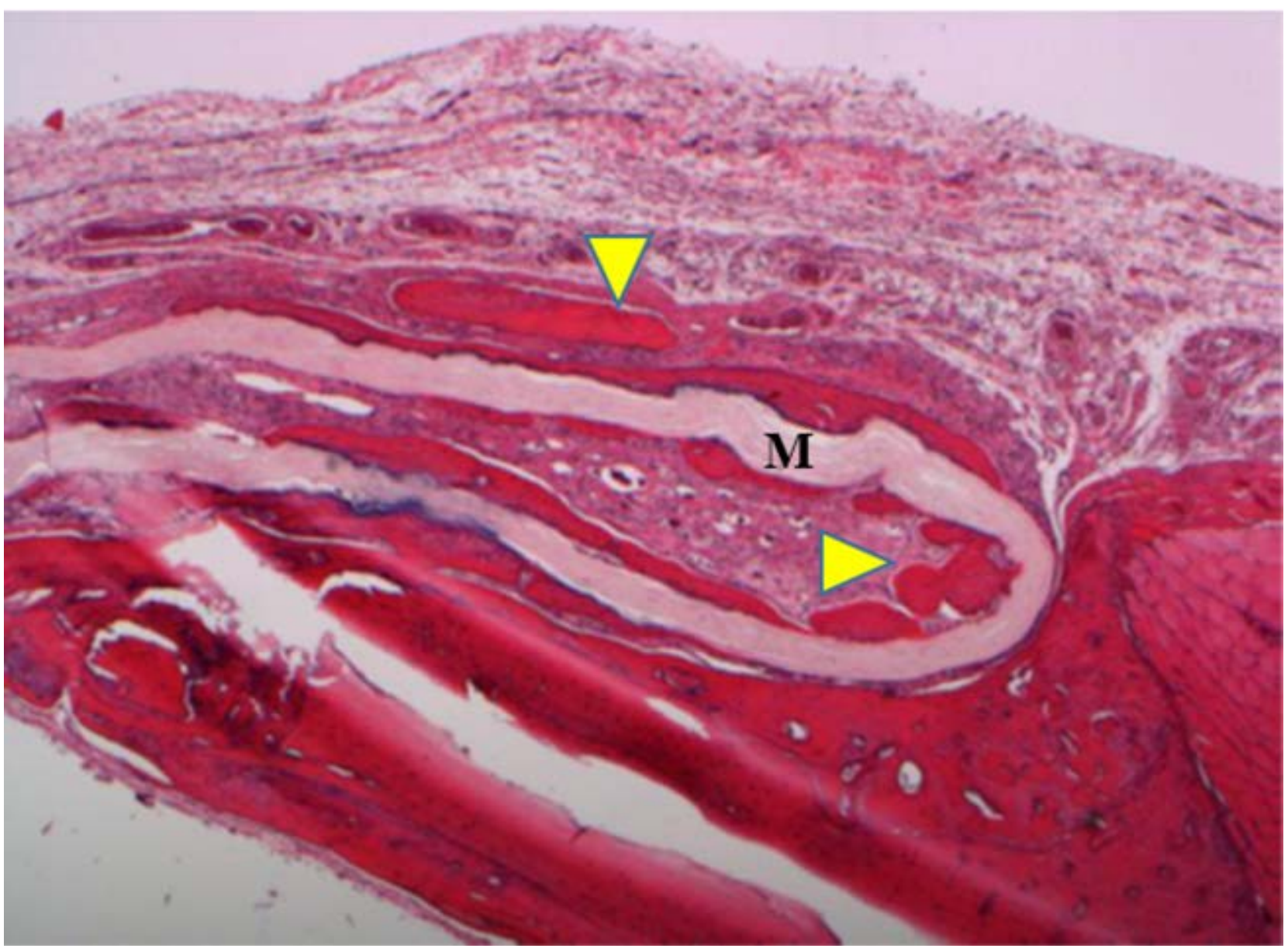

Figure 6. Histologic view of calvarial defect in control group at 8 weeks (original magnification $\times 4$ ). M: Chitosan membrane; Yellow arrows: New bone.

the defect was higher in the control group $(20.87 \pm 13.86)$ compared to experimental group $(10.08 \pm 9.87)$, though not statistically significant $(\mathrm{P}>0.05)$. New bone formation increased at 8 weeks for both groups and was slightly higher in 
the experimental group $(33.02 \pm 33.56)$ vs $(32.96 \pm 31.61)$ in the control. However, the differences were not statistically significant $(P>0.05)$.

Micro CT analysis showed apparent areas of bone formation in previously created defects indicating new bone formation at 4 weeks in both groups (Figure $7(\mathrm{~A})$ and Figure $7(\mathrm{~B}))$. Scattered radiopacities with partial and almost complete bone coverage, particularly in the control group, were seen on micro-CT at 8 weeks (Figure 3(D) and Figure 4(D)). Table 2 shows percentages of new bone volume to defect volume, new bone density and ratio of new bone surface area to bone volume. Comparable results were observed at 4 weeks in both groups. Volume and density of new bone formed in defects increased throughout the study period, although the differences between time points for both groups were not statistically significant. The control group exhibited new bone volume percentage of $(28.89 \pm 26.90)$ and density $(1.69 \pm 0.14 \mathrm{~g} / \mathrm{ml})$ at 8 weeks vs $(12.83 \pm 4.80)$ and $(1.66 \pm 0.02 \mathrm{~g} / \mathrm{ml})$ in the experimental group, respectively. The ratio of the surface area to new bone volume decreased from 4 to 8 weeks for both types of membranes and there were no differences between the membrane types.

\section{Discussion}

GBR membranes are used to enable predictable bone formation in alveolar bone. The principle characteristics of these membranes are cell occlusivity, to prevent migration of faster growing soft tissue into regenerating bone spaces, biocompatibility to not interfere with bone healing/regeneration processes and clinical manageability to enable membrane adaptation to individual defect shape. Biocompatibility is considered one of the most essential properties of regenerative membranes. Numerous in vitro and in vivo studies have shown electrospun
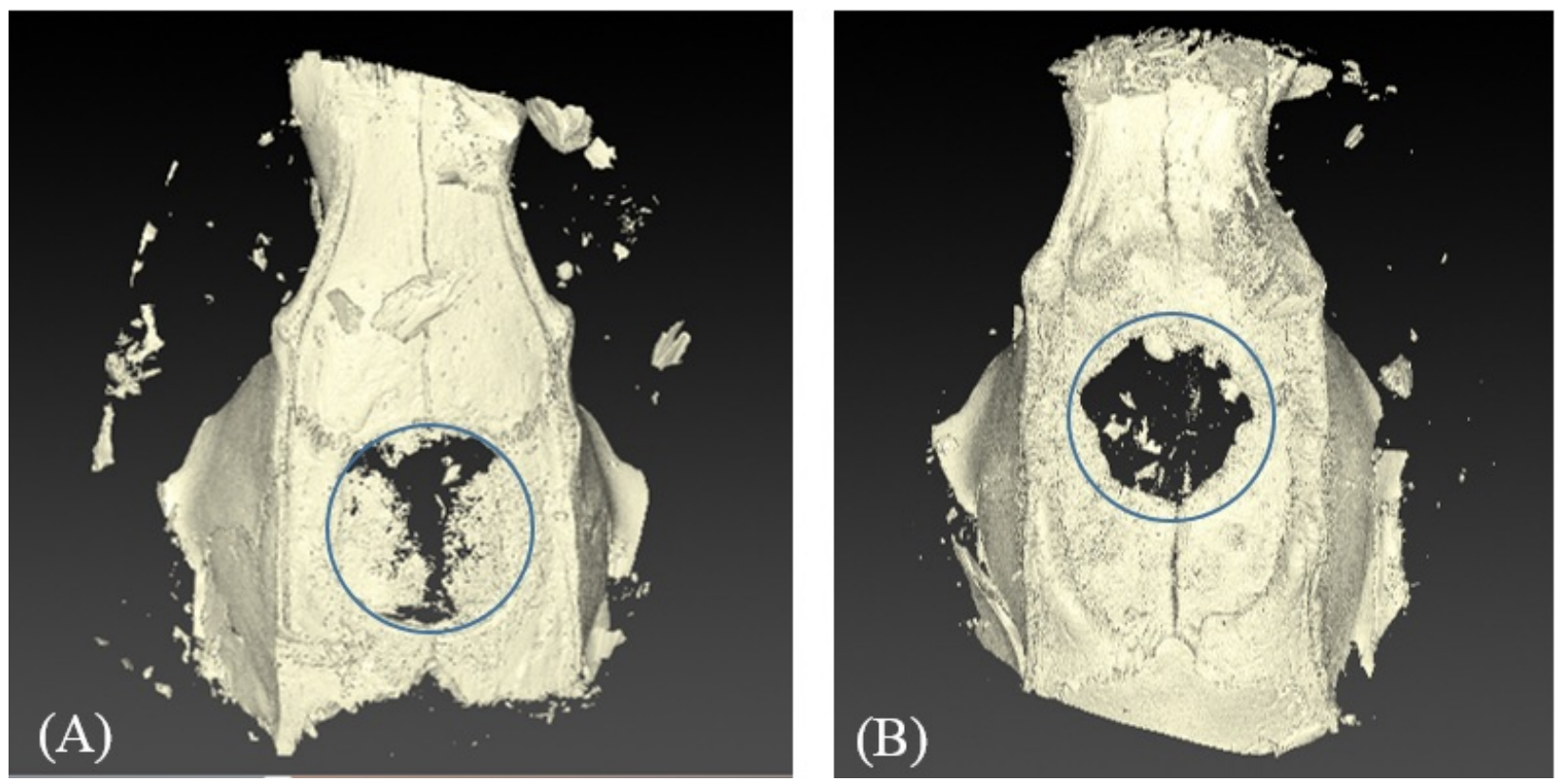

Figure 7. Micro-CT 3D models of samples at 4 weeks. (A) Control group (B) Experimental group. Blue circles represent the calvarial defects. 
chitosan nanofiber membranes to exhibit favorable biocompatibility properties by exhibiting normal healing and low inflammatory responses [12] [13] [14] [15] [16] [55] [56].

The results from this study are in agreement with previous studies citing the general biocompatibility of chitosan electrospun membranes [12] [13] [14] [15] [16] [55] [56]. In this study, no adverse effects or excessive presence of inflammatory cells, such as lymphocytes and macrophages, were found around the control or test chitosan membranes at 4 and 8 weeks. Inflammation scores indicated a normal healing response following a surgical procedure. Capillary formation continued to be present in histological sections across the different time points in both groups suggesting a high degree of membrane incorporation. These results are also consistent with previous studies by our group demonstrating in vitro and in vivo compatibility of the butyric acid modified chitosan nanofibrous membranes (BCSNF) used in this investigation [16] [54]. The butyrylation modification is used to stabilize and prevent the loss of, the nanofiber morphology of the chitosan electrospun membranes. Retaining the nanofiber structure of the membrane can mimic the natural extracellular matrix structure and provide pores to exchange nutrients while remaining cell occlusive to enhance potential in guided bone regeneration [16]. In a rodent calvarial defect model, Wu et al. reported that BCSNF membranes elicited mild to moderate inflammatory response at both 3 and 12 weeks similar to a commercial collagen control membrane group [16]. Similar results have been observed in other studies evaluating the biocompatibility of other electrospun chitosan-based membranes in in vivo bone models [12] [14] Thus, the results from these studies strongly support the conclusion that electrospun chitosan membranes have appropriate biocompatible characteristics for GBR applications.

Chitosan membranes loaded with simvastatin also exhibited minimal inflammation in our study, with good level of biocompatibility during the healing process. Previous studies have reported that local delivery of optimal dose of simvastatin had no considerable effect on inflammatory and tissue response at the targeted site [49] [52]. Nyan et al. applied simvastatin in combination with $\alpha$-tricalcium phosphate in rat calvarial defects at different doses and observed maximum bone regeneration without inducing inflammation by lowering the simvastatin dose to $0.1 \mathrm{mg}$ [49]. In addition, Similarly, Stein et al. found that locally applied simvastatin in rat mandibles stimulated significant bone growth with reduced clinical inflammation at an optimal dose of $0.5 \mathrm{mg}$ [52]. Loading chitosan membranes with simvastatin in this study did not affect tissue responses and thus did not affect the overall biocompatibility of the membranes.

Bioresorbable membranes provide a significant advantage over non resorbable membranes by eliminating the need for a reentry procedure intended for membrane removal. However, early degradation of resorbable membranes may pose a risk of losing the space for bone formation. Therefore, resorbable membranes need to retain their barrier function and maintain the space during the healing 
period. In this study, clinical observations at retrieval were consistent with the histologic evaluations revealing that both control and simvastatin loaded chitosan membranes remained intact with no significant signs of fragmentation or degradation up to 8 weeks. Even though soft tissue was in close proximity/apposition to both membrane groups, the membranes maintained their barrier function and were effective in preventing soft tissue penetration. Similar histologic observations and measurements for the amount of membrane remaining in both groups suggest that simvastatin has a negligible effect on chitosan membrane rate of degradation.

The slow degradation of the membranes was judged to be appropriate since the membranes should last in place without degradation for 4 - 6 weeks [12]. Biodegradation of chitosan is generally explained by the enzymatic activity of lysozyme and specific human chitinases that leads to the formation of oligosaccharides which can be incorporated in metabolic pathways or be further excreted [57] [58]. This slow degradation profile may be attributed in part to chitosan biostructural properties where butyrylation modification tends to make the membranes more hydrophobic and thus less susceptible to hydrolysis and enzymatic degradation. Slow degradation can be also related to the mild to moderate inflammatory response surrounding these membranes. Previously, our group also showed a favorable degradation rate of butyric acid modified chitosan membranes as compared with the control commercial collagen membranes [16]. In addition, similar results of membrane stability and degradation pattern during bone formation over a period of $8-12$ weeks were observed by Shin et al. and Su et al. where chitosan nanofiber membranes retained its shape and continuity as well as the required space for regeneration [12] [15].

In the current study, histologic and micro-CT evaluations confirmed bone formation in calvarial defects as early as 4 weeks. Initially, bony islands were seen below the membranes and thicker osseous tissue was detected at the edges of the defect. Micro-CT analysis demonstrated scattered radiopaque areas of bone formation with comparable results in both groups for all measurements. The results of early bone formation in our study are consistent with previous reports where bone formation was observed in defects at $3-4$ week time points following surgery [12] [15] [16].

Bone continued to form in the calvarial defects in both groups at 8 weeks and bridges of newly-formed bone fusing margins of defects were observed histologically. Both membranes appeared to maintain an effective barrier against soft tissue penetration allowing more healing time for localized areas of osseous tissue to connect and thicken. Bone formation was also found within the folded portions of membranes in both groups. Membrane folding can be attributed to animal movements and rubbing in the cage. Histologic observations of bone formation were quantified through histomorphometric measurements showing an increase in bone formation at 8 weeks in comparison to the 4 -week time point for both groups with no statistical significance. 
Bone formation was observed in a close proximity to membrane surface with no fibrous tissue separation. This histological finding may suggest high affinity of osteoprogenitor cells to chitosan membrane surface which may play an important role in the enhancement of osteogenesis. Previous studies reported an inhibitory effect of chitosan against fibroblasts while stimulating osteoblastic activity [7] [23] [59]. Klokkevold et al. suggested that the differentiation of osteoprogenitor cells may be potentiated by chitosan and can assist in bone formation [7]. In another study by Park et al., degraded chitosan sponges were surrounded by newly formed osseous tissue without fibrous tissue invasion [23]. It is been postulated that since chitosan has structural characteristics similar to the glycosaminoglycans, specifically hyaluronic acid, this may facilitate the migration and proliferation of osteoprogenitor cells [60]. An increased level of hyaluronic acid is a common observation in tissue repair during wound healing. The direct effect of chitosan nanofiber membranes on osteoprogenitors was observed histologically in a recent in vitro study by Lotfi et al. [14]. It was found that chitosan-nano electrospun coating of collagen membranes had an improved proliferation and metabolic activity of mesenchymal stem cells as well as higher expression of osteogenic genes (Osteocalcin, RUNX 2 and Col- $\alpha 1$ ), calcium content and alkaline phosphatase activity of these cells.

Micro-CT analysis revealed increased levels of new bone volume and density throughout the study period. The increase in density may be due either to new bone formed at a later stage or new bone formed earlier that eventually mineralized. The control group demonstrated higher values at 8 weeks in comparison with the experimental group. The micro-CT results are not in conflict since each result showed non-significant differences between the two groups. This can be due to the large standard deviation of the new bone volume of the control group.

Although, micro-CT analysis provided a widespread assessment of bone formation at different time points, only mineralized new bone in defect was detected. On the other hand, histomorphometry evaluated bone growth at the mid-sagittal section of the defect regardless of the mineralization status. As a result, less mineralized newly formed bone, that can be observed histologically, may be undetected on micro-CT. This may provide an explanation of lower micro-CT values of bone formation in comparison to histomorphometric values, particularly at early stages of bone formation.

The micro-CT bone surface to volume ratio is considered a good indicator of the active remodeling process within the bony defect. Higher bone remodeling may lead to greater bone surface with healing progression. The decrease in surface area-to-volume of new bone at 8 weeks may indicate increased bone formation in the defect along with a fair amount of osteoid remolding activity. A study by our group reported new bone volume/defect volume percentages of $37.2 \% \pm$ $22.7 \%$ and $13.6 \% \pm 7.1 \%$ calculated from histomorphometric and micro-CT data respectively for the butyric acid modified chitosan nanofibrous membranes at 12 weeks [16]. Similar to their results, our study showed comparable results of bone 
formation at an earlier time point of 8 weeks. This highlights the predictability and consistency of using nanofibrous chitosan membranes for GBR applications.

A major aim of this study was to evaluate whether the local delivery of simvastatin from the chitosan membranes may enhance the new bone formation and defect fill. The successful use of simvastatin to promote bone formation depends on the local effective concentration at the defect by using an appropriate delivery system. Numerous studies have reported that the local delivery of simvastatin from carriers such as $\alpha$-tricalcium phosphate and polylactic acid membranes lead to an increase in bone healing [49] [52]. In addition, a recent in vitro study by Gentile et al. showed a controlled localized release of simvastatin over 11 days from porous chitosan-gelatin scaffolds was needed to influence the osteoblastic proliferation and differentiation [61]. In this study, while the histomorphometric data of the simvastatin loaded membranes group showed a better bone response than that of control membranes at 8 weeks, the effect of simvastatin in bone formation was modest and not statistically significant. The reason for the difference in our result versus that of other studies is not believed to be due to the amount of simvastatin applied to the membranes since the amount used was within ranges of that used in studies demonstrating a positive effect on bone healing in calvarial defects [49] [52]. The difference is more likely due to the release kinetics of the simvastatin from the membrane. Passive absorption was used to load the simvastatin to the chitosan membranes. It may be that the simvastatin was released too quickly from the chitosan membranes and thus was not present for long enough period to impact bone healing. Alternatively, given the hydrophobic character of the chitosan membranes due to the butyrylation modification, the hydrophobic simvastatin may not have been released as levels high enough to have a therapeutic effect.

Additional studies are needed to determine the release profile of simvastatin from the chitosan membranes used in our study, as well as the ideal release profile for a beneficial effect on bone healing. The overall results should be taken with caution considering the large standard deviation of the new bone growth that was observed in both groups. Some samples yielded significant new bone formation that almost covered all the defect area, while some only showed minimal new bone even after 8 weeks. Nevertheless, results from this study suggest that chitosan nanofiber membranes may be suitable carriers for simvastatin and a viable alternative to currently utilized GBR membranes.

\section{Conclusion}

The present study tested a novel chitosan carrier system to locally deliver simvastatin to promote bone formation. Both unloaded and loaded chitosan membranes were biocompatible, with enhanced bone formation and no evidence of an adverse inflammatory reaction. Slight improved bone formation was observed with simvastatin loaded chitosan membranes, however, more studies are needed to optimize this delivery system and the kinetics of release. This study 
shows that biodegradable nanofiber chitosan membranes with and without simvastatin may be of a promising potential in the field of guided bone regeneration.

\section{Acknowledgements}

This study was funded by the University of Tennessee, College of Dentistry Alumni Fund and the College of Dentistry Unrestricted Educational Funds. Research was also supported by the Biomaterials Applications of Memphis (BAM) Research Laboratories in the Biomedical Engineering Department at the University of Memphis, Memphis, TN.

\section{References}

[1] Dahlin, C., Linde, A., Gottlow, J. and Nyman, S. (1988) Healing of Bone Defects by Guided Tissue Regeneration. Plastic and Reconstructive Surgery, 81, 672-676. https://doi.org/10.1097/00006534-198805000-00004

[2] Nowzari, H., MacDonald, E.S., Flynn, J., London, R.M., Morrison, J.L. and Slots, J. (1996) The Dynamics of Microbial Colonization of Barrier Membranes for Guided Tissue Regeneration. Journal of Periodontology, 67, 694-702. https://doi.org/10.1902/jop.1996.67.7.694

[3] Zellin, G., Gritli-Linde, A. and Linde, A. (1995) Healing of Mandibular Defects with Different Biodegradable and Non-Biodegradable Membranes: An Experimental Study in Rats. Biomaterials, 16, 601-609. https://doi.org/10.1016/0142-9612(95)93857-A

[4] Balagangadharan, K., Dhivya, S. and Selvamurugan, N. (2017) Chitosan Based Nanofibers in Bone Tissue Engineering. International Journal of Biological Macromolecules, 104, 1372-1382. https://doi.org/10.1016/j.ijbiomac.2016.12.046

[5] Kim, S.S. and Lee, J. (2014) Antibacterial Activity of Polyacrylonitrile-Chitosan Electrospun Nanofibers. Carbohydrate Polymers, 102, 231-237. https://doi.org/10.1016/j.carbpol.2013.11.028

[6] Millner, R.W., Lockhart, A.S., Bird, H. and Alexiou, C. (2009) A New Hemostatic Agent: Initial Life-Saving Experience with Celox (Chitosan) in Cardiothoracic Surgery. The Annals of Thoracic Surgery, 87, e13-e14. https://doi.org/10.1016/j.athoracsur.2008.09.046

[7] Klokkevold, P.R., Vandemark, L., Kenney, E.B. and Bernard, G.W. (1996) Osteogenesis Enhanced by Chitosan (Poly-N-acetyl glucosaminoglycan) in Vitro. Journal of Periodontology, 67, 1170-1175. https://doi.org/10.1902/jop.1996.67.11.1170

[8] Sainitya, R., Sriram, M., Kalyanaraman, V., Dhivya, S., Saravanan, S., Vairamani, M., Sastry, T.P. and Selvamurugan, N. (2015) Scaffolds Containing Chitosan/Carboxymethyl Cellulose/Mesoporous Wollastonite for Bone Tissue Engineering. International Journal of Biological Macromolecules, 80, 481-488. https://doi.org/10.1016/j.ijbiomac.2015.07.016

[9] Dhivya, S., Saravanan, S., Sastry, T.P. and Selvamurugan, N. (2015) Nanohydroxyapatite-Reinforced Chitosan Composite Hydrogel for Bone Tissue Repair in Vitro and in Vivo. Journal of Nanobiotechnology, 13, 40. https://doi.org/10.1186/s12951-015-0099-Z

[10] Yeo, Y.J., Jeon, D.W., Kim, C.S., Choi, S.H., Cho, K.S., Lee, Y.K. and Kim, C.K. (2005) Effects of Chitosan Nonwoven Membrane on Periodontal Healing of Surgi- 
cally Created One-Wall Intrabony Defects in Beagle Dogs. Journal of Biomedical Materials Research. Part B, Applied Biomaterials, 72, 86-93. https://doi.org/10.1002/jbm.b.30121

[11] Kuo, S.M., Chang, S.J., Chen, T.W. and Kuan, T.C. (2006) Guided Tissue Regeneration for Using a Chitosan Membrane: An Experimental Study in Rats. Journal of Biomedical Materials Research. Part A., 76, 408-415.

https://doi.org/10.1002/jbm.a.30534

[12] Shin, S.Y., Park, H.N., Kim, K.H., Lee, M.H., Choi, Y.S., Park, Y.J., Lee, Y.M., Ku, Y., Rhyu, I.C., Han, S.B., Lee, S.J. and Chung, C.P. (2005) Biological Evaluation of Chitosan Nanofiber Membrane for Guided Bone Regeneration. Journal of Periodontology, 76, 1778-1784. https://doi.org/10.1902/jop.2005.76.10.1778

[13] Norowski, P.A., Fujiwara, T., Clem, W.C., Adatrow, P.C., Eckstein, E.C., Haggard, W.O. and Bumgardner, J.D. (2015) Novel Naturally Crosslinked Electrospun Nanofibrous Chitosan Mats for Guided Bone Regeneration Membranes: Material Characterization and Cytocompatibility. Journal of Tissue Engineering and Regenerative Medicine, 9, 577-583. https://doi.org/10.1002/term.1648

[14] Lotfi, G., Shokrgozar, M.A., Mofid, R., Abbas, F.M., Ghanavati, F., Baghban, A.A., Yavari, S.K. and Pajoumshariati, S. (2016) Biological Evaluation (in Vitro and in Vivo) of Bilayered Collagenous Coated (Nano Electrospun and Solid Wall) Chitosan Membrane for Periodontal Guided Bone Regeneration. Annals of Biomedical Engineering, 44, 2132-2144. https://doi.org/10.1007/s10439-015-1516-Z

[15] Su, H., Liu, K.Y., Karydis, A., Abebe, D.G., Wu, C., Anderson, K.M., Ghadri, N., Adatrow, P., Fujiwara, T. and Bumgardner, J.D. (2016) In Vitro and in Vivo Evaluations of a Novel Post-Electrospinning Treatment to Improve the Fibrous Structure of Chitosan Membranes for Guided Bone Regeneration. Biomedical Materials, 12, Article ID: 015003. https://doi.org/10.1088/1748-605X/12/1/015003

[16] Wu, C., Su, H., Karydis, A., Anderson, K.M., Ghadri, N., Tang, S., Wang, Y. and Bumgardner, J.D. (2017) Mechanically Stable Surface-Hydrophobilized Chitosan Nanofibrous Barrier Membranes for Guided Bone Regeneration. Biomedical Materials, 13, Article ID: 015004. https://doi.org/10.1088/1748-605X/aa853c

[17] Khil, M.S., Cha, D.I., Kim, H.Y., Kim, I.S. and Bhattarai, N. (2003) Electrospun Nanofibrous Polyurethane Membrane as Wound Dressing. Journal of Biomedical Materials Research. Part B, Applied Biomaterials, 67, 675-679.

https://doi.org/10.1002/jbm.b.10058

[18] Rajesh, K.P. and Natarajan, T.S. (2009) Electrospun Polymer Nanofibrous Membrane for Filtration. Journal of Nanoscience and Nanotechnology, 9, 5402-5405. https://doi.org/10.1166/jnn.2009.1155

[19] Ardeshirylajimi, A., Farhadian, S., Adegani, F.J., Mirzaei, S., Zomorrod, M.S., Langroudi, L., Doostmohammadi, A., Seyedjafari, E. and Soleimani, M. (2015) Enhanced Osteoconductivity of Polyethersulfone Nanofibers Loaded with Bioactive Glass Nanoparticles in in Vitro and in Vivo Models. Cell proliferation, 48, 455-464. https://doi.org/10.1111/cpr.12198

[20] Ghorbani, F.M., Kaffashi, B., Shokrollahi, P., Seyedjafari, E. and Ardeshirylajimi, A. (2015) PCL/Chitosan/Zn-Doped nHAelectrospun Nanocomposite Scaffold Promotes Adipose Derived Stem Cells Adhesion and Proliferation. Carbohydrate Polymers, 15, 133-142. https://doi.org/10.1016/j.carbpol.2014.10.071

[21] Ardeshirylajimi, A., Dinarvand, P., Seyedjafari, E., Langroudi, L., Adegani, F.J. and Soleimani, M. (2013) Enhanced Reconstruction of Rat Calvarial Defects Achieved by Plasma-Treated Electrospun Scaffolds and Induced Pluripotent Stem Cells. Cell 
and Tissue Research, 354, 849-860. https://doi.org/10.1007/s00441-013-1693-8

[22] Mi, F.L., Tan, Y.C., Liang, H.C., Huang, R.N. and Sung, H.W. (2001) In Vitro Evaluation of a Chitosan Membrane Cross-Linked with Genipin. Journal of Biomaterials Science. Polymer Edition, 12, 835-850. https://doi.org/10.1163/156856201753113051

[23] Park, Y.J., Lee, Y.M., Park, S.N., Sheen, S.Y., Chung, C.P. and Lee, S.J. (2000) Platelet Derived Growth Factor Releasing Chitosan Sponge for Periodontal Bone Regeneration. Biomaterials, 21, 153-159. https://doi.org/10.1016/S0142-9612(99)00143-X

[24] Park, Y.J., Kim, K.H., Lee, J.Y., Ku, Y., Lee, S.J., Min, B.M. and Chung, C.P. (2006) Immobilization of Bone Morphogenetic Protein-2 on a Nanofibrous Chitosan Membrane for Enhanced Guided Bone Regeneration. Biotechnology and Applied Biochemistry, 43, 17-24. https://doi.org/10.1042/BA20050075

[25] Yun, Y.P., Kim, S.E., Kang, E.Y., Kim, H.J., Park, K. and Song, H.R. (2013) The Effect of Bone Morphogenic Protein-2 (BMP-2)-Immobilizing Heparinized-Chitosan Scaffolds for Enhanced Osteoblast Activity. Tissue Engineering and Regenerative Medicine, 10, 122-130. https://doi.org/10.1007/s13770-013-0386-4

[26] Nandi, S.K., Kundu, B. and Basu, D. (2013) Protein Growth Factors Loaded Highly Porous Chitosan Scaffold: A Comparison of Bone Healing Properties. Materials Science \& Engineering. C, Materials for Biological Applications, 33, 1267-1275. https://doi.org/10.1016/j.msec.2012.12.025

[27] Sigurdsson, T.J., Lee, M.B., Kubota, K., Turek, T.J., Wozney, J.M. and Wikesjö, U.M. (1995) Periodontal Repair in Dogs: Recombinant Human Bone Morphogenetic Protein-2 Significantly Enhances Periodontal Regeneration. Journal of Periodontology, 66, 131-138. https://doi.org/10.1902/jop.1995.66.2.131

[28] Toriumi, D.M., O’Grady, K., Horlbeck, D.M., Desai, D., Turek, T.J. and Wozney, J. (1999) Mandibular Reconstruction using Bone Morphogenetic Protein 2: Long-Term Follow-Up in a Canine Model. The Laryngoscope, 109, 1481-1489. https://doi.org/10.1097/00005537-199909000-00023

[29] Cochran, D.L., Schenk, R., Buser, D., Wozney, J.M. and Jones, A.A. (1999) Recombinant Human Bone Morphogenetic Protein-2 Stimulation of Bone Formation around Endosseous Dental Implants. Journal of Periodontology, 70, 139-151. https://doi.org/10.1902/jop.1999.70.2.139

[30] Wikesjö, U.M.E., Guglielmoni, P.G., Promsudthi, A., Cho, K.S., Trombelli, L., Selvig, K.A., Jin, L. and Wozney, J.M. (1999) Periodontal Repair in Dogs: Effect of rhBMP-2 Concentration on Regeneration of Alveolar Bone and Periodontal Attachment. Journal of Clinical Periodontology, 26, 392-400. https://doi.org/10.1034/j.1600-051X.1999.260610.x

[31] Selvig, K.A., Sorensen, R.G., Wozney, J.M. and Wikesjö, U.M. (2002) Bone Repair Following Recombinant Human Bone Morphogenetic Protein-2 Stimulated Periodontal Regeneration. Journal of Periodontology, 73, 1020-1029.

https://doi.org/10.1902/jop.2002.73.9.1020

[32] Kao, R.T., Murakami, S. and Beirne, O.R. (2009) The Use of Biologic Mediators and Tissue Engineering in Dentistry. Periodontology 2000, 50, 127-153. https://doi.org/10.1111/j.1600-0757.2008.00287.x

[33] Chan, K.A., Andrade, S.E., Boles,M., Buist, D.S.M., Chase, G.A., Donahue, J.G., Goodman, M.J., Gurwitz, J.H., LaCroix, A.Z. and Platt, R. (2000) Inhibitors of Hydroxymethylglutaryl-Coenzyme A Reductase and Risk of Fractures among Older Women. The Lancet, 355, 2185-2188. 
https://doi.org/10.1016/S0140-6736(00)02400-4

[34] Wang, P.S., Solomon, D.H., Mogun, H. and Avorn, J. (2000) HMG-CoA Reductase Inhibitors and the Risk of Hip Fractures in Elderly Patients. Journal of American Medical Association, 283, 3211-3216. https://doi.org/10.1001/jama.283.24.3211

[35] Funkhouser, H.L., Adera, T. and Adler, R.A. (2002) Effect of HMG-CoA Reductase Inhibitors (Statins) on Bone Mineral Density. Journal of Clinical Densitometry, 5, 151-158. https://doi.org/10.1385/JCD:5:2:151

[36] Kupcsik, L., Meurya, T., Flury, M., Stoddart, M. and Alini, M. (2009) Statin-Induced Calcification in Human Mesenchymal Stem Cells Is Cell Death Related. Journal of Cellular and Molecular Medicine, 13, 4465-4473. https://doi.org/10.1111/j.1582-4934.2008.00545.x

[37] Zhao, B.J. and Liu, Y.H. (2014) Simvastatin Induces the Osteogenic Differentiation of Human Periodontal Ligament Stem Cells. Fundamental \& Clinical Pharmacolo$g y$, 28, 583-592. https://doi.org/10.1111/fcp.12050

[38] Yamashita, M., Otsuka, F., Mukai, T., Otani, H., Inagaki, K., Miyoshi, T., Goto, J., Yamamura, M. and Makino, H. (2008) Simvastatin Antagonizes Tumor Necrosis Factor-Alpha Inhibition of Bone Morphogenetic Proteins-2-Induced Osteoblast Differentiation by Regulating Smad Signaling and Ras/Rho-Mitogenactivated Protein Kinase Pathway. The Journal of Endocrinology, 196, 601-613. https://doi.org/10.1677/JOE-07-0532

[39] Maeda, T., Kawane, T. and Horiuchi, N. (2003) Statins Augment Vascular Endothelial Growth Factor Expression in Osteoblastic Cells via Inhibition of Protein Prenylation. Endocrinology, 144, 681-692. https://doi.org/10.1210/en.2002-220682

[40] Ayukawa, Y., Yasukawa, E., Moriyama, Y., Ogino, Y., Wada, H., Atsuta, I. and Koyano, K. (2009) Local Application of Statin Promotes Bone Repair through the Suppression of Osteoclasts and the Enhancement of Osteoblasts at Bone-Healing Sites in Rats. Oral Surgery, Oral Medicine, Oral Pathology, Oral Radiology, and Endodontics, 107, 336-342. https://doi.org/10.1016/j.tripleo.2008.07.013

[41] Sakoda, K., Yamamoto, M., Negishi, Y., Liao, J.K., Node, K. and Izumi, Y. (2006) Simvastatin Decreases IL-6 and IL-8 Production in Epithelial Cells. Journal of Dental Research, 85, 520-523. https://doi.org/10.1177/154405910608500608

[42] Jerwood, S. and Cohen, J. (2008) Unexpected Antimicrobial Effect of Statins. The Journal of Antimicrobial Chemotherapy, 61, 362-364. https://doi.org/10.1093/jac/dkm496

[43] Pradeep, A.R. and Thorat, M.S. (2010) Clinical Effect of Subgingivally Delivered Simvastatin in the Treatment of Patients with Chronic Periodontitis: A Randomized Clinical Trial. Journal of Periodontology, 81, 214-222.

https://doi.org/10.1902/jop.2009.090429

[44] Pradeep, A.R., Priyanka, N., Kalra, N., Naik, S.B., Singh, S.P. and Martande, S. (2012) Clinical Efficacy of Subgingivally Delivered 1.2-mg Simvastatin in the Treatment of Individuals with Class II Furcation Defects: A Randomized Controlled Clinical Trial. Journal of Periodontology, 83, 1472-1479.

https://doi.org/10.1902/jop.2012.110716

[45] Priyanka, N., Abhilash, A., Saquib, S., Malgaonkar, N., Kudyar, N., Gupta, A., Kalra, N. and Pradeep, A.R. (2017) Clinical Efficacy of Subgingivally Delivered $1.2 \mathrm{mg}$ Simvastatin in the Treatment of Patients with Aggressive Periodontitis: A Randomized Controlled Clinical Trial. The International Journal of Periodontics \& Restorative Dentistry, 37, e135-e141. https://doi.org/10.11607/prd.2936

[46] Gouda, A., Helal, E., Ali, S., Bakry, S. and Yassin, S. (2017) Maxillary Sinus Lift Us- 
ing Osteoinductive Simvastatin Combined with $\beta$-TCP versus $\beta$-TCP-A Comparative Pilot Study to Evaluate Simvastatin Enhanced and Accelerated Bone Formation. Acta Odontologica Scandinavica, 76, 39-47. https://doi.org/10.1080/00016357.2017.1381345

[47] Nyan, M., Hao, J., Miyahara, T., Noritake, K., Rodriguez, R. and Kasugai, S. (2014) Accelerated and Enhanced Bone Formation on Novel Simvastatin-Loaded Porous Titanium Oxide Surfaces. Clinical Implant Dentistry and Related Research, 16, 675-683. https://doi.org/10.1111/cid.12045

[48] Mundy, G., Garrett, R., Harris, S., Chan, J., Chen, D., Rossini, G., Boyce, B., Zhao, M. and Gutierrez, G. (1999) Stimulation of Bone Formation in Vitro and in Rodents by Statins. Science, 286, 1946-1949. https://doi.org/10.1126/science.286.5446.1946

[49] Nyan, M., Sato, D., Kihara, H., Machida, T., Ohya, K. and Kasugai, S. (2009) Effects of the Combination with Alpha-Tricalcium Phosphate and Simvastatin on Bone Regeneration. Clinical Oral Implants Research, 20, 280-287. https://doi.org/10.1111/j.1600-0501.2008.01639.x

[50] Qi, Y., Zhao, T., Yan, W., Xu, K., Shi, Z. and Wang, J. (2013) Mesenchymal Stem Cell Sheet Transplantation Combined with Locally Released Simvastatin Enhances Bone Formation in a Rat Tibia Osteotomy Model. Cytotherapy, 15, 44-56. https://doi.org/10.1016/j.jcyt.2012.10.006

[51] Jiang, L., Sun, H., Yuan, A., Zhang, K., Li, D., Li, C., Shi, C., Li, X., Gao, K., Zheng, C., Yang, B. and Sun, H. (2013) Enhancement of Osteoinduction by Continual Simvastatin Release from Poly(lacticco-glycolic acid)-hydroxyapatite-simvastatin Nano Fibrous Scaffold. Journal of Biomedical Nanotechnology, 9, 1921-1928. https://doi.org/10.1166/jbn.2013.1692

[52] Stein, D., Lee, Y., Schmid, M.J., Killpack, B., Genrich, M.A., Narayana, N., Marx, D.B., Cullen, D.M. and Reinhardt, R.A. (2005) Local Simvastatin Effects on Mandibular Bone Growth and Inflammation. Journal of Periodontology, 76, 1861-1870. https://doi.org/10.1902/jop.2005.76.11.1861

[53] Lee, Y., Schmid, M.J., Marx, D.B., Beatty, M.W., Cullen, D.M., Collins, M.E. and Reinhardt, R.A. (2008) The Effect of Local Simvastatin Delivery Strategies on Mandibular Bone Formation in Vivo. Biomaterials, 29, 1940-1949. https://doi.org/10.1016/j.biomaterials.2007.12.045

[54] Wu, C., Su, H., Tang, S. and Bumgardner, J.D. (2014) The Stabilization of Electrospun Chitosan Nanofibers by Reversible Acylation. Cellulose, 21, 2549-2556. https://doi.org/10.1007/s10570-014-0306-3

[55] Norowski, P.A., Mishra, S., Adatrow, P.C., Haggard, W.O. and Bumgardner, J.D. (2012) Suture Pullout Strength and in Vitro Fibroblast and RAW 264.7 Monocyte Biocompatibility of Genipin Crosslinked Nanofibrous Chitosan Mats for Guided Tissue Regeneration. Journal of Biomedical Materials Research. Part A, 100, 2890-2896. https://doi.org/10.1002/jbm.a.34224

[56] Bavariya, A.J., Andrew Norowski, P., Mark Anderson, K., Adatrow, P.C., Garcia-Godoy, F., Stein, S.H. and Bumgardner, J.D. (2014) Evaluation of Biocompatibility and Degradation of Chitosan Nanofiber Membrane Crosslinked with Genipin. Journal of Biomedical Materials Research. Part B, Applied Biomaterials, 102, 1084-1092. https://doi.org/10.1002/jbm.b.33090

[57] Pangburn, S.H., Trescony, P.V. and Heller, J. (1982) Lysozyme Degradation of Partially Deacetylated Chitin, Its Films and Hydrogels. Biomaterials, 3, 105-108. https://doi.org/10.1016/0142-9612(82)90043-6

[58] Funkhouser, J.D. and Aronson, N.N. (2007) Chitinase Family GH18: Evolutionary 
Insights from the Genomic History of a Diverse Protein Family. BioMed Central Evolutionary Biology, 7, 96.

[59] Muzzarelli, R., Biagini, G., Pugnaloni, A., Filippini, O., Baldassarre, V., Castaldini, C. and Rizzoli, C. (1989) Reconstruction of Periodontal Tissue with Chitosan. Biomaterials, 10, 598-603. https://doi.org/10.1016/0142-9612(89)90113-0

[60] Adzick, N.S. and Longaker, M.T. (1992) Characteristics of Fetal Tissue Repair. In: Adzick, N.S. and Longaker, M.T., Eds., Fetal Wound Healing, Elsevier Science Publishing Co., Inc., New York, 53-70.

[61] Gentile, P., Nandagiri, V.K., Daly, J., Chiono, V., Mattu, C., Tonda-Turo, C., Ciardelli, G. and Ramtoola, Z. (2016) Localised Controlled Release of Simvastatin from Porous Chitosan-Gelatin Scaffolds Engrafted with Simvastatin Loaded PLGA-Microparticles for Bone Tissue Engineering Application. Materials Science \& Engineering. C, Materials for Biological Applications, 59, 249-257.

https://doi.org/10.1016/j.msec.2015.10.014 